\title{
Strength of British English accents in altered listening conditions
}

\author{
PETER HOWELL \\ University College London, London, England \\ WILLIAM BARRY \\ University of the Saarland, Saarbrücken, Germany \\ and \\ DAVID VINSON \\ University College London, London, England
}

\begin{abstract}
This work is concerned with the processing or representational level at which accent forms learned early in life can change and with whether alteration to a speaker's auditory environment can elicit an original accent. In Experiment 1, recordings were made of an equal number of (1) speakers living in the home counties (HC) of Britain (around the London conurbation) who claimed to have retained the accent of the region that they originally had come from, (2) speakers who stated that they had lost their regional accent and acquired an $\mathrm{HC}$ accent, and (3) native HC speakers. They read two texts in a normal listening environment. Listeners rated the similarity in accent between each of these texts and all the other texts. The results showed that in the normal listening conditions, the speakers who had lost their accent were rated as being more similar to HC English speakers than to those speakers from the same region who had retained their accent. In Experiment 2, recordings of the same speakers under frequency-shifted and delayed auditory feedback, as well as the normal listening conditions used earlier, were rated in order to see whether the manipulations of listening environment would elicit the speaker's original accent. Listeners rated similarity of accent in a sample of speech recorded under normal listening against a sample read by another speaker in one of the altered listening conditions. When listening condition was altered, the speakers who had lost their original accent were rated as more similar to those who had retained their accent. It is concluded that accent differences can be elicited by altering listening environment because the speech systems of speakers who have lost their accent are more vulnerable than those of speakers who have not changed their original accent.
\end{abstract}

The term accent as referred to in this study applies to the pronunciation, as opposed to the grammatical and lexical composition, of utterances (Hughes \& Trudgill, 1996; Wells, 1982). In this sense, every utterance is pronounced with an accent, which may be judged to be posh, standard, foreign, etc. Thus, a regional accent may be discerned whether or not the choice of word forms is regional (Brennan \& Brennan, 1981a, 1981b). Accent is usually perceived and identified as such when the pronunciation differs from what a person is used to. However, the term is commonly restricted to deviations from some defined standard. We are using it in this sense, inasmuch as we refer to regional pronunciations as accented, in contrast to a home counties (HC) pronunciation.

The way in which accents differ can be described at different linguistic levels. First, there are prosodic and segmental differences, the former referring to lexical or phrasal stressing or accentuation patterns and intonation,

Correspondence concerning this article should be addressed to P. Howell, Department of Psychology, University College London, Gower St., London WC1E 6BT, England (e-mail: p.howell@ucl.ac.uk). and the latter referring to the realization of consonants and vowels. ${ }^{1}$ Second, there are phonological versus phonetic differences, the former involving differences in the sound systems, such as missing or additional sound oppositions (e.g., the absence of a difference between fair and fur in Liverpool English), and the latter involving the way the properties are realized within the same framework of op-

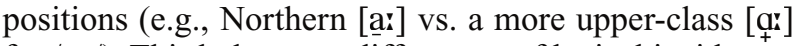
for $/ \mathbf{a}: /)$. Third, there are differences of lexical incidence, where the same or a similar framework of oppositions exists but the lexical items in which the equivalent sounds occur differ (e.g., ladder, brass, and father, which have the $/ \mathfrak{a} /, / \mathbf{a} \mathbf{z} /$, and $/ \mathbf{a}: /$ phonemes, respectively, in HC British English but the $/ \mathfrak{a} /, / \mathfrak{a} /$, and /a: / phonemes, respectively, in Northern English accents).

In this article, we investigate some aspects of how accent change occurs. A speaker who was born, brought up, and remains in a local language region almost always has the accent of the area of his or her own part of the country. When speakers with British regional accents relocate to different parts of the British Isles, they often acquire the accent of the adopted region. But it is common to observe that speakers who have left the region in which 
they grew up and have acquired another accent as adults revert to their original accent when that accent is being spoken around them. How much this applies to accents lost in childhood and at what age of accent abandonment the reversion no longer occurs have not, to our knowledge, been investigated (but see Bongaerts, Mennen, \& Slik, 2000; Bongaerts, Planken, \& Schils, 1997; and Flege, 1999 , for discussions of age effects in second-language pronunciation learning). Accent change is one manifestation of the well-established phenomenon of speakers accommodating to the communicative context (Beebe \& Giles, 1984; Giles \& Smith, 1979), which has both influenced research methodology and defined research questions in sociolinguistics (Labov, 1986). Within the specifically British social context, changes in accent may arise out of a desire to communicate more effectively in the destination region. Regional accents of British English signal social distinctions, and although accents are becoming less closely linked with social strata, the avoidance of social stigma remains one factor behind accent change. In the British Isles, speakers who change their accent to increase their social standing frequently adopt an HC English accent (the accent spoken in the region of England around London), the form widely used in the spoken media.

There are other (involuntary) ways in which accent may change. In speakers who have changed their accent, situations may exist that cause them to revert (partially) to their original accent. Informal observation suggests that alterations to the sound of a speaker's voice can bring this about. Two such alterations (change to frequency content and to timing of speech) are examined in the experiments below. Telephones make such alterations to the voice (as well as changes in its intensity). When a speaker uses a telephone, frequency and intensity change, and these alterations may explain why an accent appears to sound stronger. Also, a speaker's original accent reemerges in older speakers who have adopted the accent of a different part of their country. Again, this may be due to frequency and intensity changes in auditory reception that occur as speakers get older (presbyacusis). The influence that a change in timing has is also supported by a number of informal observations. Thus, untrained actors have problems maintaining an imitated accent in echoey or noisy auditoria. Cellular phones have appreciable delays, so the emergence of accent on this type of equipment may be a result of alteration to timing.

There has been one experimental study that examined whether altering the listening environment can cause a speaker to revert to his or her original accent. Howell and Dworzynski (2001) investigated whether delayed auditory feedback (DAF) and frequency-shifted feedback (FSF) would elicit an accented form of English in speakers who had an original language other than English (German speakers speaking English). They showed that the German accent of the German speakers speaking English was more marked when they were subjected to these two forms of alteration to their listening environment. They explained their results in terms of the speakers' having multiple re- sponse forms for a language (the initial one based on their native language and one that was a closer approximation to that of the acquired language). According to Howell and Dworzynski, speakers may revert to the early form even after they have become proficient in the acquired language. A potential problem in this study is that even the speech of a fluent speaker who has not changed his or her original accent is affected when the listening environment is altered. The judgments of listeners may have been based on the effects of alterations to the listening environment on speech output, rather than specifically on accent changes brought about by the change in the listening conditions. Howell and Dworzynski minimized this possibility by performing several analyses to verify that their listeners were judging accent and not other effects that the altered listening environment might have brought about.

In the experiments reported in this article, two questions about accent change were addressed. (1) Do listeners judge that the adopted accent of speakers who are living in London and who believe that they have lost their original accent is closer to HC English than is the accent of speakers who claim to have retained their accent? (2) Does the accent of speakers who report having lost their accent reappear when listening conditions are altered? In addition to answering these questions, the results also have implications as to whether listeners are specifically able to judge accent change when it is induced by changes in the listening environment (Howell \& Dworzynski, 2001).

\section{EXPERIMENT 1}

As was stated earlier, HC English is the reference accent for many speakers, since it is widely used in the media. All of the speakers involved in both of the present experiments have lived in London for some time, making it probable that their adopted accent is HC English. Also, those speakers who believe they have lost their accent often regard themselves as using an accent approximating HC English. This experiment tested whether the speech of speakers who have lost their original accent is judged to be more similar to the HC English accent than is the speech of those speakers who retain their accent.

The texts used for the experiment were constructed so as to provide sufficient potential differences between the accents being examined to make the measurement of a shift in accent strength viable. The texts exploited the potential differences between accents discussed abovenamely, differences in phonemic oppositions, in the lexical incidence of phonemes, or in the phonetic realization of phonemes. Clearly, the segmental features of an accent (i.e., the consonant and vowel realizations) are only part of what allows a regional or social accent to be identified. Rhythmic patterning (Ling, Grabe, \& Nolan, 2000) -in particular, intonational features (Grabe, 2002; Grabe, Post, Nolan, \& Farrar, 2000) - is the suprasegmental (prosodic) accompaniment to the speech-sound structure of any utterance. This, in addition to the accent carried on 
the segmental features of the vowels and consonants, may reflect the regional origin of the speaker. Naturally, the prosody enters into a listeners' judgments of similarity or difference of accent, but as was argued above, it is an integral part of any realized utterance and is, therefore, a legitimate part of the overall impression of regional accent strength that is being investigated. Thus, although the subjects' regionally varying prosody was not controllable through the structure of these texts, this did not affect the validity of the intergroup comparisons under the different feedback conditions. The study by Howell and Dworzynski (2001), in which the foreign accent of speakers who spoke English as a second language was judged under different auditory feedback conditions, showed that segmental text definition is a satisfactory predictor of potential accent deviation.

The technique used to establish proximity to an $\mathrm{HC}$ English accent was a factorial ANOVA, with which we investigated listeners' ratings of accent similarity between speakers with $\mathrm{HC}$ accents and speakers with regional accents as a function of regional accent group and loss/ retention of that regional accent. Investigation of accent variability at the individual level was also performed, using the average linkage hierarchical clustering algorithm to illustrate the overall patterns among ratings of speaker accent similarity. This produced a tree structure (dendrogram) that reflected the proximity of different accents. If the prediction of the experiment is upheld, the speakers who have lost their original accent should lie closer to HC English speakers than do those speakers who have retained their accent, demonstrated by a strong main effect of accent loss/retention in the ANOVA and illustrated by the clustering performance of individual speakers.

\section{Method}

The method of the experiment is described in two parts. The first concerns speaker selection, materials used, and recording details. The second gives details of the perceptual judgments made by the listeners.

Speakers for recordings. Twenty speakers who live and work in London were used (4 for each of five original accents, including HC English). ${ }^{2}$ These were volunteers, who came from five regions with distinct accents (Wells, 1982): Northern Ireland (NI), lowland Scotland (SC), Liverpool (LI), and Newcastle (NC), as well as the $\mathrm{HC}$. None of the speakers reported speech or hearing problems, nor had they received specialized instruction (e.g., for acting or teaching purposes) about their speech. Individual details about the speakers are given in Table 1. Accent region is indicated in column 1. For each of the regional accents, 2 speakers reported that they had lost their original accent (coded as "--"), and 2 reported that they had retained their original accent (coded as “+”). This self-reported accent status was checked empirically in the analyses.

Columns 2 and 3 give gender ( 14 of them male, and 6 female) and age (ranging from 21 to 57 years), respectively. Column 4 indicates time spent in London (in years). In all cases, the years spent in London were contiguous and occurred in the period immediately prior to when the recordings were made. Column 5 gives time spent in another region of the United Kingdom (in years). With one proviso, all the speakers lived exclusively in their original accent region and then in London so the "other region" in column 5 is the accent designation area for speakers with regional accents. The exception is for periods
Table 1

Details for the 20 Speakers Used in Experiments 1 and 2

\begin{tabular}{|c|c|c|c|c|c|}
\hline $\begin{array}{l}\text { Accent } \\
\text { Region }\end{array}$ & Gender & Age & $\begin{array}{l}\text { Time in } \\
\text { London }\end{array}$ & $\begin{array}{l}\text { Time in } \\
\text { Region }\end{array}$ & $\begin{array}{l}\text { Provincial } \\
\text { University }\end{array}$ \\
\hline NI- & M & 23 & 9 & 11 & Y \\
\hline NI- & M & 32 & 7 & 22 & Y \\
\hline $\mathrm{NI}+$ & M & 24 & 6 & 15 & Y \\
\hline $\mathrm{NI}+$ & M & 49 & 26 & 20 & Y \\
\hline $\mathrm{SC}-$ & M & 24 & 8 & 13 & Y \\
\hline $\mathrm{SC}-$ & M & 35 & 22 & 10 & Y \\
\hline $\mathrm{SC}+$ & M & 24 & 6 & 18 & $\mathrm{~N}$ \\
\hline $\mathrm{SC}+$ & M & 21 & 7 & 14 & $\mathrm{~N}$ \\
\hline LI- & F & 28 & 8 & 20 & $\mathrm{~N}$ \\
\hline LI- & M & 46 & 25 & 18 & Y \\
\hline LI+ & M & 57 & 34 & 23 & $\mathrm{~N}$ \\
\hline LI+ & F & 47 & 17 & 30 & $\mathrm{~N}$ \\
\hline $\mathrm{NC}-$ & F & 48 & 35 & 13 & $\mathrm{~N}$ \\
\hline $\mathrm{NC}-$ & F & 23 & 5 & 15 & Y \\
\hline $\mathrm{NC}+$ & F & 25 & 7 & 18 & $\mathrm{~N}$ \\
\hline $\mathrm{NC}+$ & M & 30 & 14 & 16 & $\mathrm{~N}$ \\
\hline $\mathrm{HC}$ & $\mathrm{F}$ & 23 & 21 & 2 & $\mathrm{~N}$ \\
\hline $\mathrm{HC}$ & M & 34 & 31 & 0 & Y \\
\hline $\mathrm{HC}$ & M & 39 & 36 & 0 & Y \\
\hline $\mathrm{HC}$ & M & 52 & 48 & 1 & Y \\
\hline
\end{tabular}

Note-Accent region: NI, Northern Ireland; SC, lowland Scotland; LI, Liverpool; NC, Newcastle; HC, home counties. A - signifies a lost accent, and a + signifies a retained accent; this is not applicable to $\mathrm{HC}$ speakers. When a speaker had attended a provincial university, this was for 3 years. Time spent in region represents time in the accent region plus time at a provincial university (where appropriate).

that were spent away from London for purposes of study at provincial universities (i.e., universities outside London). These periods away always occurred between the ages of 18 and 22, and the regions the speakers went to varied from those selected for the experiment. Column 6 indicates whether time was spent at a provincial university outside the designated accent region. So, for instance, this shows that 2 of the 4 HC English speakers have lived all their lives in London, except for 3-year periods at provincial universities. Most speakers with regional accents initially came to London to study and subsequently stayed there. The speakers were chosen so as to be heterogeneous, in order to reflect, to a limited extent, the range of accents in a region. Longer amounts of time spent in London do not necessarily lead speakers to lose their accent (e.g., the third Liverpool speaker had spent 34 years in London but had retained his accent).

Materials. Two texts were generated that contained words with consonants and vowels whose phonemic function and/or phonetic realization potentially distinguished the regional accents of the speakers from one another and from HC English.

The design constraints on the texts can be illustrated by the following simplified example (Table 2) with three accent regions (Home Counties, NC, and LI). In this example, it is assumed that HC English manifests one feature that NC English and LI English do not and that distinguishes it from them when it occurs in the text. LI English has a second feature that distinguishes it from $\mathrm{HC}$ and NC English, and a third feature distinguishes NC from LI and HC English.

It is also assumed, for this illustration, that the features are used all the time by speakers of the particular accent and are, therefore, reliable markers. Of course, one feature alone can rarely uniquely identify an accent; it is the combination that provides the profile. The number of accent features determines the degree of difference between accents. This leads to a third assumption - namely, that the presence or absence of a feature is a defining property of an accent. Since a phonetic feature implies articulatory and acoustic properties, the absence of a particular feature implies a change of articulatory pattern and a change of acoustic identity. 
Table 2

Illustration of Idealized Set of Features (hc, nc, and li) That Separate Home Counties (HC), Newcastle (NC), and Liverpool (LI) English Accents, Respectively

\begin{tabular}{cccc}
\hline & \multicolumn{3}{c}{ Accent } \\
\cline { 2 - 4 } Feature & HC & NC & LI \\
\hline hc & + & - & - \\
li & - & - & + \\
nc & - & + & - \\
\hline
\end{tabular}

Obviously, the assumptions behind this feature characterization of regional accents represent a simplification, but material that includes features that have a statistical tendency to operate in this way can be used to differentiate accents. To illustrate the nature of the idealiza-

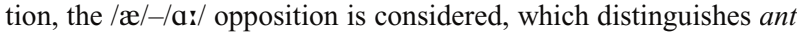
(/ænt/) and aunt (/a:nt/) in HC English, but not in many Northern English accents (transcriptions are given in SIL Doulos IPA 93 notation throughout this article). A Northern English speaker may well abandon the ant-aunt homophony, producing a long vowel in aunt and other words (e.g., glass, pass, fast, or last). However, even though the HC English distinction is adopted, it does not necessarily mean that the HC English vowel timbre is produced. There is a Northern English long-A vowel in such words as father, farther, palm, calm, and so forth that is realized phonetically with a more "fronted" (palatal) quality: [fạ:ðə], [pha:m], and so forth. Adopting the long $\mathrm{A}$ for words that have a short $\overline{\mathrm{A}}$ in Northern English and a long A in HC English, while retaining the Northern English long-A quality, is a change in the direction of an HC English accent, but the resulting accent is still likely to be judged as different from it.

A wide sample of accent features was used in the prepared texts (see Appendix A for phonetic descriptions and a table showing their distribution across the accents). They were derived from the descriptions of British accents given by Wells (1982), Hughes and Trudgill (1996), and Foulkes and Docherty (1999). Two texts (given in Appendix B) were generated using 17 features, with the primary goal of achieving a roughly equal difference weighting between $\mathrm{HC}$ English and the regional accents, but also with the aim of separating the regional accents.

The features on which the composition of the texts was based separate each of the regional accents more or less equally from $\mathrm{HC}$ English in terms of the number of distinguishing features, but the feature distances between the regional accents themselves vary (Table 3). This is linguistically inevitable because the accents did not arise so as to be equidistant from one another, and it is historically inevitable because some accents are more closely linked. Thus, SC and NI English can be seen, as was expected, to be closer than are LI English and either SC or NI English.

In summary, the feature inventory defining the accents provided a basis for the generation of the accent-differentiating texts, and it provided a framework against which to evaluate the perceptual similarity of the accents to listeners. The feature distances between the accents are an abstract statement of difference potential; they cannot predict the degree to which any speaker may realize that potential. However, this was immaterial within the present study, since it was not intended to analyze the individual speakers' phonetic realizations in comparison with HC English but merely to locate them within the accent space relative to HC English and to ascertain (in Experiment 2) whether their position in that space would be affected by a modification of the auditory feedback conditions.

The material was, however, also subjected to an auditory phonetic scrutiny that confirmed a difference in the strength of regional accent concomitant with the claims of the speakers. Residual accent in speakers who reported that they had lost their accent varied from almost nonexistent to slight; it was moderate to strong in those who claimed to have retained their accent. Typical residual features were identifiable in the SC and NI /av/, the LI and NC short cen- tral realization of $\mathrm{HC} / \mathrm{a}$ / in words such as glass, the LI retention of $/ \mathrm{ng} /$ where HC English has $/ \mathrm{y} /$ (singer, thing), and the use of a closer rounded vowel (close to $[\mathrm{U}]$ ) for $\mathrm{HC} / \Lambda$, as in $h u t$. In only one speaker, an NI English speaker who reported that he had retained his accent, were there recognizable traces of a regional intonation. This general lack of regionally differentiated intonation may be attributable to the reading task.

Procedure for recordings. The two texts were both read under normal listening conditions. (The speakers were also recorded under DAF and FSF conditions at the same recording session. These procedures will be described in the Method section for Experiment 2, since these recordings were not used in the present experiment). All the recordings were made in an AVTEC Amplisilence sound-treated booth. Speech was transduced with a Sennheiser K6 microphone and recorded on a DAT recorder. The recordings were transferred digitally to a PC for the perceptual tests.

Listeners. Eight listeners were recruited, 4 of them male and 4 female, between 18 and 25 years of age (mean age, 20.3 years). None reported a history of speaking or hearing problems, and none had any special speaking or listening training. All were native to London and normally resided in that city.

Procedure for perceptual tests. The listeners heard two texts for all 190 possible pairings of the 20 speakers. The text used was selected randomly, and the speakers in a test pair were also selected randomly, subject to the constraint that each pair of speakers was heard once only. The selected pair of texts was played to the listener over headphones. They were instructed to listen to the text to judge the similarity of accent on a difference-rating scale of 1-7 (1, same; 7, different). Apart from being told to rate accent similarity, the listeners were not given any further instructions about how to make the judgments. The listeners could hear the texts as often as they desired, and they were self-paced to avoid fatigue. A complete assessment of the 190 pairings took approximately $4 \mathrm{~h}$. All ratings were made on the same day, to avoid long-term changes in accent judgments.

\section{Results}

The degree of reliability of the ratings between participants was high (Cronbach's $\alpha=.970$ across the 8 listeners), ensuring that idiosyncratic differences between listeners contributed little to their decisions about accent similarity. Similarity ratings were averaged across listeners, yielding one value per speaker pairing. All the speaker pairings involving $\mathrm{HC}$ accents were selected for the first analysis. The four speakers with $\mathrm{HC}$ accents were rated as extremely similar overall (across all possible pairings, $M=1.33, S D=0.39$ ). For each non-HC speaker, similarity to each of the four $\mathrm{HC}$ speakers was assessed, as is reported in Table 4.

A factorial ANOVA was conducted upon the mean ratings for similarity to $\mathrm{HC}$ speakers, using $\mathrm{HC}$ speaker as a random factor, and investigating the effects of accent group (LI, NC, NI, or SC) and accent retention (lost or retained).

Table 3 Distances Between Accents

\begin{tabular}{lcccc}
\hline & NC & SC & NI & HC \\
\hline LI & 9 & 14 & 16 & 7 \\
NC & - & 11 & 9 & 6 \\
SC & - & - & 2 & 8 \\
NI & - & - & - & 9 \\
\hline
\end{tabular}

Note-The distances are based on the 17 features specified in the second part of Appendix A. NC, Newcastle; SC, lowland Scotland; NI, Northern Ireland; HC, home counties; LI, Liverpool. 
Table 4

Average Similarity Ratings Between Home Counties English Speakers and Speakers With Regional Accents, as a Function of Regional Accent Group and Self-Reported Accent Loss or Retention

\begin{tabular}{lcccc}
\hline & \multicolumn{4}{c}{ Region } \\
\cline { 2 - 5 } & LI & NC & NI & SC \\
\hline Lost accent & 3.40 & 2.57 & 4.46 & 4.04 \\
Retained accent & 6.66 & 6.22 & 6.49 & 6.82 \\
\hline
\end{tabular}

Note-LI, Liverpool; NC, Newcastle; NI, Northern Ireland; SC, lowland Scotland.

The main effect of accent group was significant $[F(3,56)=$ $3.330, p=.026]$, reflecting overall differences in the similarity between different regional accents and $\mathrm{HC}$ accents. Given the limited number of speakers investigated, these results could simply indicate gradations in accent loss, rather than quantitative differences between accent groups in this task. The main effect of accent retention was also significant $[F(1,56)=113.983, p<.001]$, indicating that, overall, the speakers who self-reported having lost their accents were indeed rated as more similar to $\mathrm{HC}$ speakers than were the speakers who had retained their accents. The interaction between accent group and accent loss was not significant $[F(3,56)=1.609, p=.198]$, indicating that accent loss was behaviorally comparable across regional accent groups.

Average similarity ratings between accents under normal feedback were taken and subjected to hierarchical clustering, using the average linkage algorithm, in order to establish the patterns of similarity among accents in normal listening conditions.
Figure 1 indicates the similarity properties among the accents. Similarity between speakers is indicated by the point on the $x$-axis at which vertical connections occur. For example, the $2 \mathrm{HC}$ speakers depicted at the bottom of Figure 1 are connected by a vertical marker at a value of 1.0, indicating the similarity value between these speakers. The group made up by these two very similar speakers is then connected to the next $\mathrm{HC}$ speaker at a value of about 1.2, indicating the average similarity between these 2 speakers and the 3rd. In a similar manner the next connection (with the last $\mathrm{HC}$ speaker), at a value of about 1.5 , indicates that the latter speaker is rated, on the average, as 1.5 units away from the other $3 \mathrm{HC}$ speakers (but provides no further details about which of those speakers is more or less similar). Arrangement of speakers along the $y$-axis is determined by group average similarity, as depicted by their vertical connections. The figure illustrates not only the high similarity between the $4 \mathrm{HC}$ speakers (clustered together at the bottom of the figure), but also an overall correspondence between speakers' ratings of their accent loss/retention and listeners' similarity ratings. Most of the speakers who claimed to have lost their accents cluster with the HC speakers, and those who claimed to have retained their accents cluster far from the HC speakers. To summarize, speakers' judgments about whether or not they had lost their regional accents were largely reflected in the average similarity judgments.

\section{Discussion}

The results of the ANOVA and the similarity dendrogram obtained from the hierarchical clustering analysis indicate that HC English speakers separate from other

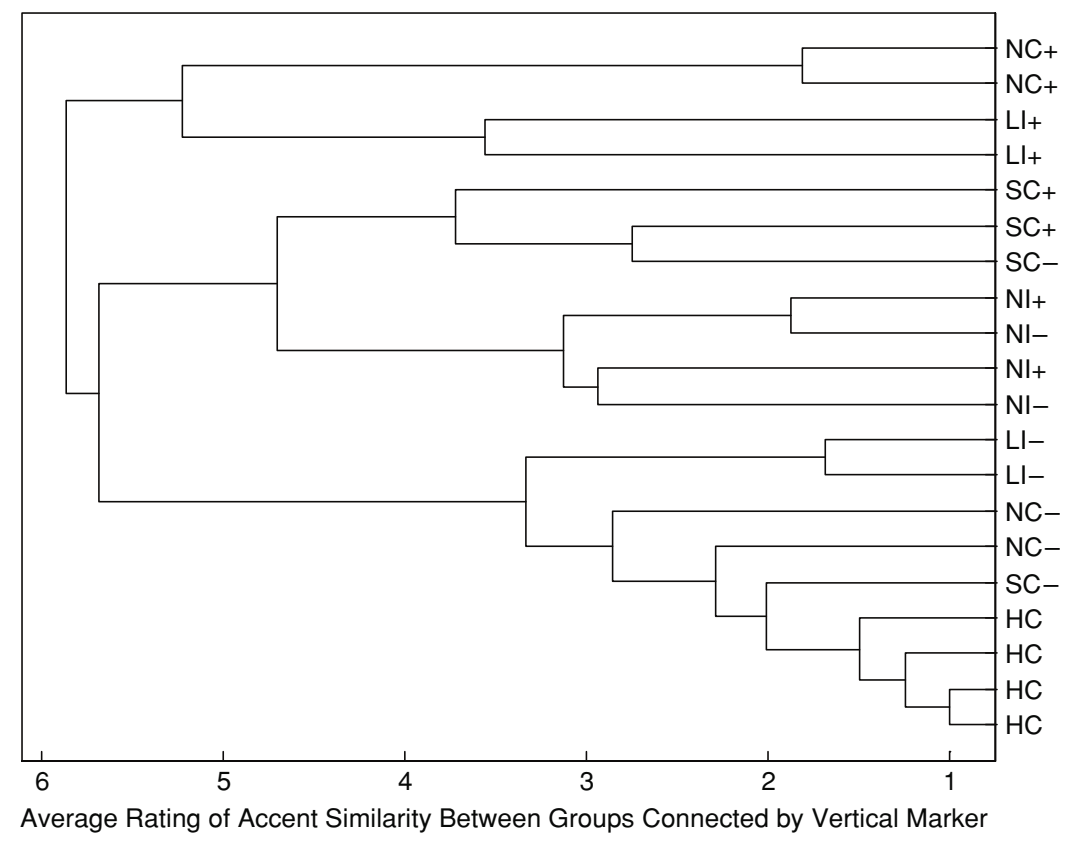

Figure 1. Similarity tree for subjects under normal listening conditions. A + indicates a speaker who has retained the regional accent; a - indicates a speaker who has lost the regional accent. HC, home counties; LI, Liverpool; NC, Newcastle; NI, Northern Ireland; SC, lowland Scotland. 
accent groups. Speakers who reported that they had lost their accent tended to be rated as more similar and, thus, occupied a position closer to HC English speakers than did their accent counterparts who believed that they had retained their accent.

The texts were clearly successful in distinguishing accents and, also, in differentiating perceived distances between accents. Of course, it is not possible to say which of the assumed regional features lay behind the judgments or what their relative perceptual effect might have been for the listeners. Graded phonetic attributes such as the Northern shift of short /æa/ and the long /az/, discussed above, from a front and back vowel quality, respectively, to a more central quality, are likely to be important triggers for regional accent identification, although they were not captured with the mainly categorical type of descriptor used here. There is graded exponency of accents in terms of the realization quality of the phenomenon being investigated. So, although there is a degree of latitude in the realization of, for example, /æ/ (particularly since HC English now accepts a more open, slightly centralized quality), at some point the degree of centralization would be too Northern and would then signal non-HC English. This variable phonetic quality of the /æ/ words was, however, not captured in our features, which represented the categorical presence or lack of a difference between word pairs such as lass and glass. In this case, either the glass vowel is long, or it is as short as the vowel in lass.

It appears (given the success of the analysis) that these accompanying gradient properties varied randomly across accent types, so they did not make some accents more apparent than others. The auditory-phonetic examination of the recordings reveals that the degree to which a regional accent was present varied to some extent within, as well as between, the unmodified and modified groups. The modified group can be described generally as retaining residual phonetic properties of the type discussed above, particularly in terms of vowel quality, having mainly adopted the standard phonemic oppositions.

These findings show that the text is suitable for revealing accent differences and that the self-report of these speakers is, in most cases, a reasonable reflection of whether accent has been lost or retained. The question of whether changing the listening environment elicits an original accent (operationalized as a shift in similarity patterns by speakers who retain their accent) will be addressed next.

\section{EXPERIMENT 2}

In Experiment 1, the majority of the speakers who believed that they had lost their accents were rated as closer to HC English than were their counterparts who claimed to have retained their accent. Positioning of the speakers who had lost their accent close to HC English permitted the effects of alteration to the listening conditions on the speakers' accents to be established in the present experiment.

It was predicted that, when speaking under DAF and FSF conditions, speakers who had lost their original regional accent (as demonstrated in Experiment 1) would be rated as less similar to $\mathrm{HC}$ English and more similar to the speakers who had retained their regional accent when the latter spoke under DAF and FSF conditions. This specific shift in position in perceptual space toward original regional accent when the listening environment was altered would support the view that accent reemerges, rather than speech under alteration simply being judged as sounding odd (see the discussion of Howell and Dworzynski's [2001] results in the introduction).

\section{Method}

Materials. The recordings of the NI, SC, LI, NC, and HC English speakers made for Experiment 1 were also used in Experiment 2. HC English is the accent that these speakers adopted when they gave up their original regional accent. The speakers in the accent groups were the same as those in the previous experiment (4 speakers per group). Two speakers in each accent group believed that they had lost their accent, and 2 speakers that they had retained their accent. The speech from the normal listening environment (used in Experiment 1) was used, as well as speech produced in DAF and FSF environments.

In the DAF condition, the subjects heard their own speech binaurally at a 66-msec delay over Sennheiser HD480II headphones. Level over the headphones was set at about $70 \mathrm{~dB}$ SPL and was periodically checked. A Digitech Model Studio 400 signal processor produced the DAF delays. The subjects were told that they would hear their voice altered over the headphones, which they should ignore. A Sennheiser K6 microphone was used to record vocal responses directly onto a DAT recorder for use in the analysis, as in normal listening conditions. The output of an additional Sennheiser K6 microphone was relayed via a Quad microphone amplifier to the Digitech Model Studio 400 signal processor to produce the required signal alteration. This was then played back with a 6 -dB gain.

In the FSF condition, the speakers heard their own speech frequency modified. Again, the Digitech signal processor was used to modify the original speech signal, shifting the whole speech spectrum down by half an octave.

Listeners. Thirty-two listeners were recruited for the experiment, none of whom had taken part in the first experiment. They were selected according to the criteria outlined in Experiment 1 . Their ages ranged from 18 to 27 years, and there were equal numbers of listeners of each sex. The listeners were randomly assigned to one of four conditions ( 8 listeners per group).

Procedure for perceptual tests. The experiment was designed to prevent the listeners from learning a speaker's accent under altered listening conditions and then employing it to make decisions about that speaker's accent when in normal listening conditions. To achieve this, no listener heard a speaker under both a normal and an altered listening condition. There were four groups of listeners, each of which heard the samples of 2 speakers in an accent group under normal listening conditions and the other 2 under one of the altered listening conditions. One speaker in each pair believed that he or she had retained his or her original accent, whereas the other considered that he or she had lost the original accent. Allocation of speakers and the listening conditions they spoke under was constant for a listening group, and only one type of altered listening condition was heard by each listener group (FSF for Groups 1 and 2 and DAF for Groups 3 and 4). Whether a speaker was heard in a normal or an altered listening condition was counterbalanced across Groups 1 and 2 and across Groups 3 and 4, to ensure that there was nothing unusual about the speakers selected to be heard under DAF or FSF. This design also ensured equal numbers of accented/unaccented samples in each listening group. Thus, the four listening groups were differentiated by type of altered listening and by which speakers they heard under altered listening. The procedure for listening to accent pairs and making similarity judgments was the same as that in Experiment 1. In order to rule out the possibility that any differences in results were due to 
the presence of speech under altered feedback, similarity judgments for pairs of speakers in normal feedback for each testing group were also assessed to determine whether the pattern of similarity obtained in Experiment 1 was replicated. This was necessary to ensure that any accent group differences were not due to the different composition of the items in the present experiment.

\section{Results}

First, as in Experiment 1, interrater reliability was assessed for each of the four groups of listeners, in order to determine the extent to which idiosyncratic variation among speakers affected ratings of accent similarity. Responses of listeners in each of the four groups correlated highly (Cronbach's $\alpha$ values $=.987, .989, .991, .992$ ).

Next, the listeners' ratings of speakers under normal feedback conditions were assessed, in order to rule out the possibility that differences were due to distortions of speech resulting from speaking under manipulated feedback. Average similarity ratings for pairings in the different feedback conditions were combined across the four listener groups and were assessed as in Experiment 1 (see Table 5).

For the normal feedback conditions, as in Experiment 1, the $\mathrm{HC}$ speakers were rated as extremely similar $(M=1.11)$; an ANOVA contrasting accent group and loss/retention of regional accent again revealed a strong effect of accent loss/ retention under normal feedback conditions $[F(3,128)=$ $333, p<.001]$. These results demonstrate that speakers with accent loss were indeed perceived as more like the $\mathrm{HC}$ speakers than were those speakers who retained their accent, despite the possible differences due to the variation in rating contexts between Experiments 1 and 2.

Analyses were then conducted to investigate ratings in the altered feedback conditions. Similarity ratings were compared directly to assess the extent to which altered feedback produced more regional-sounding accents than did speakers who reported losing their accents. It should first be pointed out that, even under altered feedback conditions, the listeners continued to rate different $\mathrm{HC}$ speakers as extremely similar (average ratings of 1.21 in the DAF condition and of 1.13 in the FSF condition). This is

Table 5

Average Similarity Ratings Between Home Counties English Speakers and Speakers With Regional Accents as a Function of Regional Accent Group and Self-Reported Accent Loss or Retention, Under Different Conditions of Feedback

\begin{tabular}{lllll}
\hline \multirow{2}{*}{ Condition } & \multicolumn{4}{c}{ Region } \\
\cline { 2 - 5 } \multicolumn{1}{c}{ LI } & NC & NI & SC \\
\hline$\quad$ Normal feedback & & & & \\
$\quad$ Lost accent & 3.27 & 4.23 & 4.53 & 2.54 \\
$\quad$ Retained accent & 6.94 & 6.77 & 6.86 & 6.91 \\
$\quad$ Delayed auditory feedback & & & & \\
$\quad$ Lost accent & 6.78 & 6.35 & 6.09 & 6.17 \\
$\quad$ Retained accent & 6.89 & 6.88 & 6.84 & 6.94 \\
$\quad$ Frequency-shifted feedback & & & & \\
$\quad$ Lost accent & 6.23 & 5.84 & 5.00 & 5.84 \\
$\quad$ Retained accent & 6.98 & 6.94 & 6.82 & 6.92 \\
\hline
\end{tabular}

Note-LI, Liverpool; NC, Newcastle; NI, Northern Ireland; SC, lowland Scotland. important, since it indicates that altered feedback does not universally reduce similarity among speakers.

Because retained-accent speakers were rated as extremely dissimilar to HC speakers in all three feedback conditions, the following analyses will focus only upon those speakers who had lost their regional accents. First, a $3 \times 4$ ANOVA was conducted upon similarity ratings to HC speakers, investigating the effects of feedback type (normal, DAF, or FSF) and accent group (NC, NI, LI, or SC). There was no main effect of accent group $[F(3,116)=$ $1.515, p=.214]$. There was a main effect of feedback condition $[F(2,116)=61.589, p<.001]$. Further investigation showed that similarity to $\mathrm{HC}$ accents was greatest under normal feedback and least under DAF (all feedback conditions significantly differed, $p<.05$ ). These effects were qualified by a significant interaction $[F(6,116)=3.624$, $p=.002]$, so that the greatest effects of altered feedback were observed for the accents that were rated as most similar to $\mathrm{HC}$ accents under normal feedback conditions.

These results demonstrate that lost accents diverge from $\mathrm{HC}$ accents under altered feedback, but it is still necessary to demonstrate that altered feedback produces speech that is more similar to the original accent. To test this directly, similarity ratings for lost-accent speakers were compared with the averaged judgments of similarity to (1) the HC English speakers and (2) his/her accented counterpart. If speakers show signs of their lost accents under altered feedback conditions, this should be revealed as less similarity to HC English speakers (as illustrated above), coupled with greater similarity to the speaker who has retained his/her accent. The different accent groups were combined for this analysis, in which a two-factor repeated measures ANOVA was used to investigate comparison group (two levels: similarity of a speaker to same regional accent speakers or similarity to HC English speakers) and feedback condition (three levels: normal feedback, DAF, or FSF).

The main effect of accent group was significant overall $[F(1,7)=11.571, p=.011]$, reflecting greater similarity between lost-accent speakers and those with the corresponding regional accent than to the HC English speakers across all feedback conditions. The main effect of feedback condition was also significant $[F(2,14)=7.394, p=$ $.006]$, indicating differences in similarity across feedback conditions. These main effects, however, were qualified by a significant interaction $[F(2,14)=12.582, p=.001]$. Investigation of simple main effects revealed that lostaccent speakers were rated as being more similar to those speakers who had retained their accents, but only under conditions of altered feedback. This is shown in Table 6, where average similarity ratings between lost-accent speakers and other speakers are given for each auditory feedback condition. Under normal listening conditions, the similarity rating between speakers who had lost their accent and those who had retained their accent did not differ from the rating between speakers who had lost their accent and HC English speakers, illustrating that these speakers still retained some aspects of their original accents. On the other hand, under DAF and FSF, similar- 
Table 6

Average Similarity Ratings Between Lost-Accent Speakers and Other Speakers as a Function of Auditory Feedback Condition

\begin{tabular}{lcc}
\hline & \multicolumn{2}{c}{ Similarity to } \\
\cline { 2 - 3 } Condition & $\begin{array}{c}\text { Same Regional } \\
\text { Accent }\end{array}$ & $\begin{array}{c}\text { Home } \\
\text { Counties }\end{array}$ \\
\hline Normal listening & 3.74 & 3.62 \\
Delayed auditory feedback & 2.67 & 5.71 \\
Frequency-shifted feedback & 2.64 & 6.33
\end{tabular}

Note-All speakers who self-reported having lost their accents were included. 1, most similar; 7, least similar.

ity ratings between speakers who had lost their accents were more similar to those for speakers from the same region and less similar to those for HC English speakers. Crucially, this effect was present when the speakers' own opinions of whether they had lost their regional accents or not, which was not always reflected in the listeners' ratings of similarity, were used.

Similarity dendrograms were then prepared as in Experiment 1 . Because the speakers were divided into two groups, in order to allow the investigation of normal versus altered feedback, two separate figures are presented for each feedback contrast (corresponding to entirely different sets of speakers). The similarity clustering among speakers is given in Figure 2 for normal feedback, in Figure 3 for the DAF condition, and in Figure 4 for the FSF condition. These figures clearly indicate that with only a single exception (one lost-accent NI English speaker in the DAF condition, NI- in the left panel of Figure 3), the speakers who had lost their accents now exhibited extremely strong tendencies to cluster with the accented speakers, rather than with those from the HC English group, under conditions of altered feedback. These results converge in indicating accent shifts away from an HC English accent toward a stronger regional accent under altered feedback; this overall trend was also confirmed in the auditory-phonetic examination. The change was manifested either in a greater frequency of features already present in the recordings without modified feedback (e.g., /ng/ in one LI speaker) or more extreme variants of non-HC English vowel realization). In no cases were there recognizable regional intonation patterns, presumably because all the speakers raised the average pitch and loudness and spoke with an extremely restricted pitch range - in some cases, almost monotonous - as a reaction to the altered feedback. Since these effects applied as much to the HC English speakers as to the other regional speakers, it must be concluded that the judgments were based primarily on the segmental changes.

The literature on foreign language learning suggests that (1) there are only weak effects of length of residence on pronunciation proficiency but that (2) first-language accent retention tends to be stronger in older than in younger second-language learners. The data from Experiments 1 and 2 were examined by regression analyses to check whether similar regularities are true for the acquisition of a new accent. The analyses were made irrespective of designation of the subjects as having lost or retained their accent. In all the regression analyses, the dependent
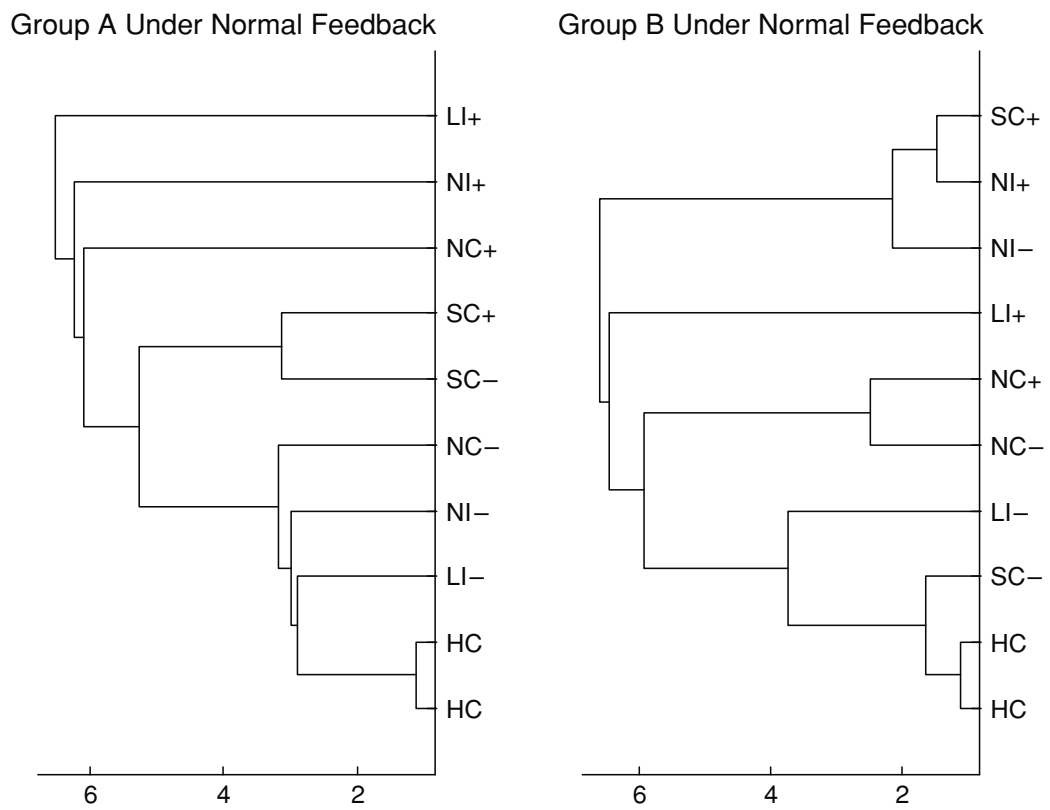

Figure 2. Similarity tree for subjects under normal listening conditions. The speakers were divided into two groups for the rating task, depicted in the left and right panels. A + indicates a speaker who has retained the regional accent; $\mathbf{a}$ - indicates a speaker who has lost the regional accent. HC, home counties; LI, Liverpool; NC, Newcastle; NI, Northern Ireland; SC, lowland Scotland. 

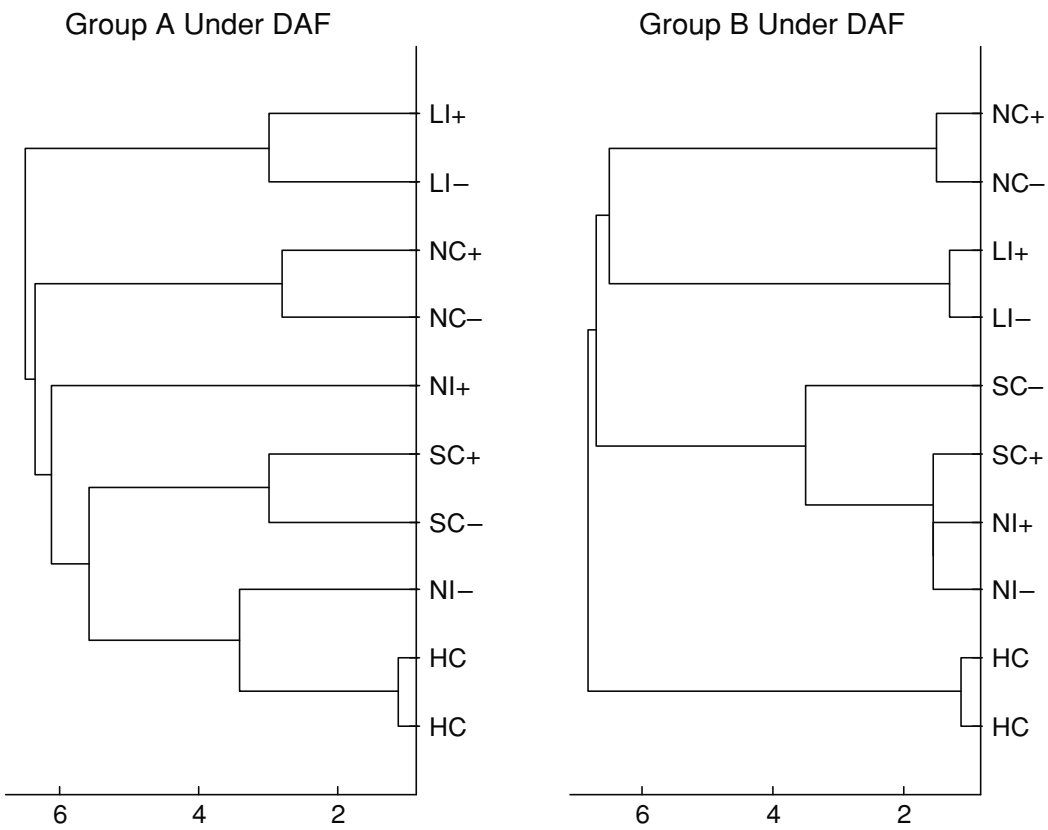

Figure 3. Similarity tree for subjects under delayed auditory feedback (DAF) conditions. The speakers were divided into two groups for the rating task, depicted in the left and right panels. A + indicates a speaker who has retained the regional accent; a - indicates a speaker who has lost the regional accent. HC, home counties; LI, Liverpool; NC, Newcastle; NI, Northern Ireland; SC, lowland Scotland.

variable was the average rating of a given speaker's similarity to the HC speakers in the corresponding feedback condition, excluding HC-to-HC comparisons. The data available from Experiment 1 were the source of the similarity ratings under normal feedback. The data available from Experiment 2 were the source of the similarity ratings for normal feedback, DAF, and FSF (the last two allowed examination of what age factors related to degree of accent change under altered feedback conditions).

In agreement with Observation 1, the length of time spent in London did not correlate significantly with similarity ratings to $\mathrm{HC}$ for any of the listening conditions. Thus, for speakers who move to London later than in their teens, there is no greater chance of acquiring an $\mathrm{HC}$ accent than there would be had they spent longer in London.

There was also support for Observation 2. Table 1 shows that speakers who lost their accent were younger, on average, when they came to London than were speakers who retained their accent. This parallels the observation that first-language accent retention tends to be stronger in older than in younger foreign language learners. To see whether older speakers are more likely to retain their accent, length of time in a non-HC accent region was correlated with similarity to the $\mathrm{HC}$ accent. There was evidence that the longer a person had spent in the non-HC region, the more dissimilar was his or her accent to the $\mathrm{HC}$ accent. This relationship held up under one of the feedback conditions (DAF). Thus, time spent in a region was significantly correlated (negatively) with rated similarity to $\mathrm{HC}$ accents in the normal listening conditions in Experi- ment $1[r(16)=.475, p=.031$, one tailed] and Experiment $2[r(16)=.538, p=.015$, one tailed $]$ and for the DAF condition in Experiment $2[r(16)=.573, p=.01$, one tailed].

\section{Discussion}

The first experiment showed that speakers who reported that they had lost their original accents were rated as being more similar to HC English speakers in normal listening conditions. The speakers who had lost their accents shifted position under each of the altered listening conditions (DAF and FSF), so that they were now rated as being much more similar to the speakers who had retained the same original accent. This shows that an original accent reemerges (the speakers who had lost their accent now occupied a position in perceptual space closer to the speakers who still had that accent form). From this, it appears that altering listening condition has a specific effect on restoring accent. This, along with the observation that the $\mathrm{HC}$ speakers consistently clustered very closely together under all three feedback conditions, rules out the potential problem, raised in connection with Howell and Dworzynski's (2001) experiment, that speech under altered listening conditions might be judged as generally odd sounding, rather than as reflecting the speaker's original accent.

An objection may be raised that these results show a lack of consistency in the number of features separating an accent from HC English, as identified by the features in Table 3 for the different regional accents, and the relative perceptual distance of that accent from the $\mathrm{HC}$ accent and 

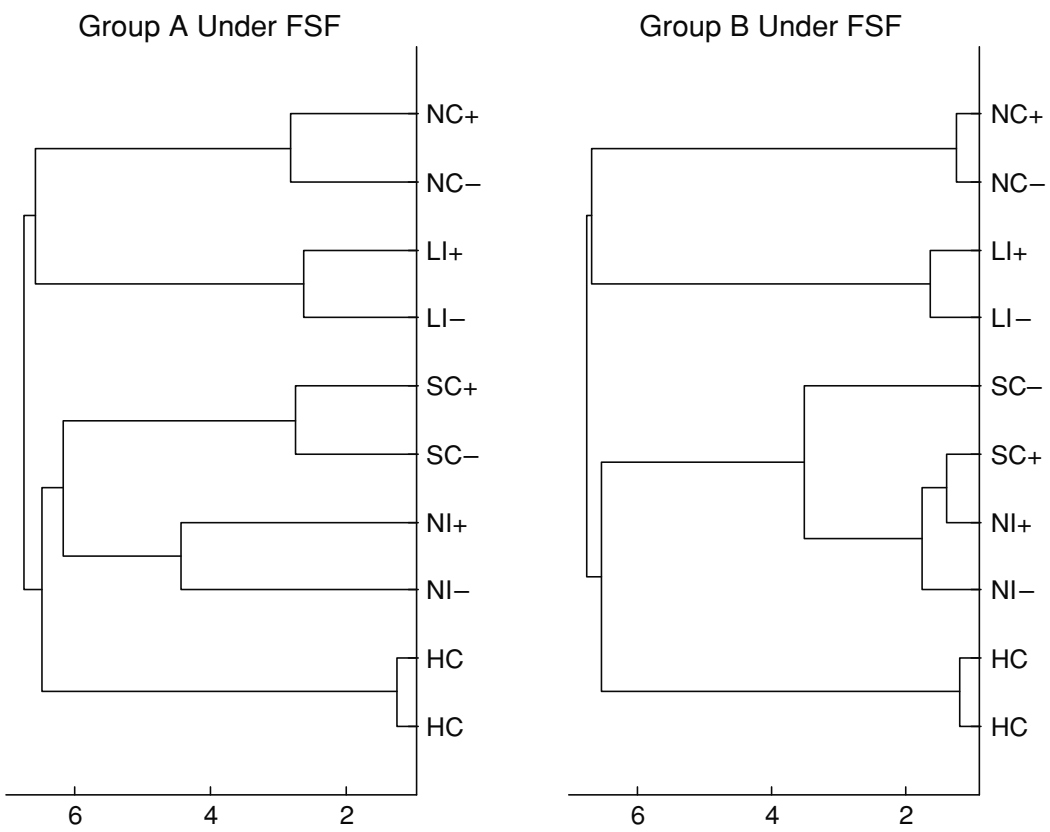

Figure 4. Similarity tree for subjects under frequency-shifted feedback (FSF) conditions. The speakers were divided into two groups for the rating task, depicted in the left and right panels. A + indicates a speaker who has retained the regional accent; a - indicates a speaker who has lost the regional accent. HC, home counties; LI, Liverpool; NC, Newcastle; NI, Northern Ireland; SC, lowland Scotland.

from other regional accents. However, the complex nature of the accent-defining features as (1) phonological differences with accompanying phonetic realization differences, on the one hand, and (2) purely phonetic realization differences with no implications for the phonological system, on the other, means that both the degree of phonetic deviation and the perceptual salience of that deviation can vary considerably. An example is the marked difference between LI and NI accents in the number of features separating them from the $\mathrm{HC}$ accent, whereas their perceptual difference from the $\mathrm{HC}$ accent (and from each other) is much less.

\section{GENERAL DISCUSSION}

Experiment 1 showed that speakers who reported that they had lost their original regional accent were rated as being more similar to HC English speakers than were speakers who had retained their accent. Experiment 2 showed that the speakers who had lost their original regional accent were rated as being closer to speakers who had retained the same regional accent when they were speaking with DAF or FSF. The findings from the two experiments reported above have implications for our view both on the status of regional accent in speech production in general and on the function of auditory feedback in speech production.

Considering the phenomenon of accent within a general sociopsychological framework, these results provide supporting evidence for the informal observations of shifting accent as a product of ambient auditory conditions. More specifically, the results throw some light on the role of auditory information during speech production. A widely accepted view of speech motor control (Perkell et al., 2000; Perkell et al., 1997; Perkell, Matthies, Svirsky, \& Jordan, 1995) holds that the establishment of links between auditory feedback, on the one hand, and tactile and kinesthetic feedback patterns, on the other, is important at the acquisition stage (Borden, 1980; Guenther, 1995; see also Perkell, Lane, Svirsky, \& Webster, 1992, for learning in cochlear implant patients) but that auditory feedback cannot logically play a role in moment-to-moment control of speech-sound production, simply because it occurs too long after the event. Studies showing the very slow deterioration of segmental control after hearing loss (Cowie \& Douglas-Cowie, 1992; Hamlet, Stone, \& McCarthy, 1976; Lane \& Webster, 1991) provide confirmation for this assumption. In the light of this evidence, it would appear surprising that speakers change their accent by generating new articulatory patterns in the short term as a result of modified auditory feedback.

The fact that speakers can change their accent long term (Experiment 1) but that an accent closer to their original accent can be elicited over the short term (Experiment 2) implies that the alternative accent forms are available to speakers who have changed their accent. It was argued in the introduction that elicitation of an accent that is not currently in use by a speaker suggests that the response forms used in that particular accent remain available. Administration of DAF or FSF reactivates the original accent 
form. Similar short-term switches to earlier pronunciation patterns as a result of changes in auditory feedback conditions have been observed in deaf subjects with cochlear implants when the aid is switched off (Lane, Wozniak, Matthies, Svirsky, \& Perkell, 1995; Perkell et al., 2000). The interpretation in these studies was that two different internal models for response output exist in parallel. When the auditory feedback information is not sufficient to verify the quality of the speech that is to be produced according to the more recently acquired model, the subject falls back on the more robust model acquired first.

If the argument is that different models for responses are available, alteration to the listening environment must also affect a low level of speech control (where speakers select alternative responses). This is consistent with a recent view about the effects of alterations to listening environment on speech control (Howell, 2002). Other authors consider, however, that alteration to listening conditions has its effect at higher planning levels in the central nervous system (e.g., Postma, 2000). It is also possible that accent influences these higher levels. Thus, people can recognize accents perceptually, and accent features interact with central parts of the cognitive system, such as word-frequency effects (Foulkes \& Docherty, 1999). Although the findings that listeners can detect accents perceptually cannot be disputed, this is relevant to production of accent only if one assumes that production is linked with perception (e.g., as in a feedback monitoring account, where the speaker listens to his or her own speech to verify its output). There are many problems for such an account (Howell, 2002), such as the observation that a speaker who loses his or her hearing can continue to control speech (Borden, 1979, 1980; Cowie \& Douglas-Cowie, 1992; Hamlet et al., 1976; Lane $\&$ Webster, 1991). The effects of word frequency on accent (Foulkes \& Docherty, 1999), nevertheless, support the view that higher central nervous system levels are involved in accent control. Thus, further work is needed to establish at what level or levels accent control occurs.

An interesting post hoc finding in the present study was the fact that not only were the subjects who had retained their regional accent the ones who had come to the London area later in life, but also that there was a link between the age of the subjects who claimed to have lost their regional accent and their distance from the $\mathrm{HC}$ reference accent under altered feedback conditions. This seems to parallel the findings in second-language and foreign language learning research, which has demonstrated the more native-like pronunciation in the foreign language and the greater resistance to interference from a first language of those learners who had been exposed to and learned the foreign language at a younger age (for an overview, see, e.g., Flege, 1999; Olson \& Samuels, 1973). However, the trend in the present study is not perfectly consistent, nor is the sample of speakers large enough to make sense of deviations from the expected pattern. However, the apparently more robust evidence from foreign language acquisition may also not be understood as a hard and fast rule. Recent work by Bongaerts and his associates at Nijmegen (Bongaerts et al., 2000; Bongaerts et al., 1997) has shown that the age factor is not inevitably dominant and that there are adult learners who are capable of acquiring native-like pronunciation. The strength of a person's motivation to be integrated into the community is apparently a further (complex) factor. How strong the parallels are between second-language pronunciation learning and the modification of a first-language accent and how robust a native-like second-language pronunciation is to disruptive auditory conditions remain open questions for future research.

\section{REFERENCES}

Beebe, L. M., \& Giles, H. (1984). Speech-accommodation theories: A discussion in terms of second-language acquisition. International Journal of the Sociology of Language, 46, 5-32.

Bongaerts, T., Mennen, S., \& Slik, F. V. D. (2000). Authenticity of pronunciation in naturalistic second language acquisition: The case of very advanced late learners of Dutch as a second language. Studia Linguistica, 54, 298-308.

Bongaerts, T., Planken, B., \& Schils, E. (1997). Age and ultimate attainment in the pronunciation of a foreign language. Studies in Second Language Acquisition, 19, 447-465.

BORDEN, G. (1979). An interpretation of research on feedback interruption in speech. Brain \& Language, 7, 307-319.

Borden, G. (1980). Use of feedback in establishing and developing speech. Speech \& Language, 3, 223-242.

Brennan, E. M., \& Brennan, J. S. (1981a). Accent scaling and language attitudes: Reactions to Mexican-American English speech. Language \& Speech, 24, 207-221.

Brennan, E. M., \& Brennan, J. S. (1981b). Measurements of accent and attitude toward Mexican-American speech. Journal of Psycholinguistic Research, 10, 487-501.

Cowie, R. L., \& Douglas-Cowie, E. (1992). Postlingually acquired deafness: Speech deterioration and the wider consequences. New York: Mouton de Gruyter.

FLege, J. E. (1999). Age of learning and second-language speech. In D. P. Birdsong (Ed.), Second language acquisition and the critical period hypothesis (pp. 101-132). Hillsdale, NJ: Erlbaum.

Foulkes, P., \& Docherty, G. (1999). Urban voices: Accent studies in the British Isles. London: Arnold.

Giles, H., \& Smith, P. M. (1979). Accommodation theory: Optimal levels of convergence. In H. Giles \& R. St. Clair (Eds.), Language and social psychology (pp. 45-65). Baltimore: University Park.

Grabe, E. (2002). Variation adds to prosodic typology. In B. Bel \& I. Marlien (Eds.), Proceedings of the 1st International Conference on Speech Prosody (pp. 127-132). Tokyo: Keikichi Hirose Laboratory.

Grabe, E., Post, B., Nolan, F., \& Farrar, K. (2000). Pitch accent realisation in four varieties of British English. Journal of Phonetics, 28, 161-185.

GuEnther, F. H. (1995). A modeling framework for speech motor development and kinematic articulator control. In Proceedings of the XIIIth International Congress of Phonetic Sciences (Vol. 2, pp. 9299). Stockholm: KTH and Stockholm University.

Hamlet, S. L., Stone, M. L., \& McCarthy, T. (1976). Persistence of learned motor patterns in speech. Journal of the Acoustical Society of America, 60, S66.

HoweLL, P. (2002). The EXPLAN theory of fluency control applied to the treatment of stuttering by altered feedback and operant procedures. In E. Fava (Ed.), Pathology and therapy of speech disorders (Current Issues in Linguistic Theory series, pp. 95-118). Amsterdam: Benjamins.

HowELL, P., \& DwORZYNSKI, K. (2001). Strength of German accent under altered auditory feedback. Perception \& Psychophysics, 63, 501-513.

Hughes, A., \& Trudgill, P. (1996). English accents and dialects: An introduction to social and regional varieties of English in the British Isles (3rd ed.). London: Arnold.

LABOv, W. (1986). Sources of inherent variation in the speech process. In J. S. Perkell \& D. H. Klatt (Eds.), Invariance and variability in speech processes (pp. 402-423). Hillsdale, NJ: Erlbaum. 
Lane, H., \& Webster, J. (1991). Speech deterioration in postlingually deafened adults. Journal of the Acoustical Society of America, 89, 859-866.

Lane, H., Wozniak, J., Matthies, M. L., Svirsky, M. A., \& Perkell, J. (1995). Phonemic resetting versus postural adjustments in the speech of cochlear implant users: An exploration of voice-onset time. Journal of the Acoustical Society of America, 98, 3096-3106.

Ling, L. E., GRABE, E., \& Nolan, F. (2000). Quantitative characterizations of speech rhythm: Syllable-timing in Singapore English. Language \& Speech, 43, 377-401.

Olson, L., \& SAMUELS, S. J. (1973). The relationship between age and accuracy of foreign language pronunciation. Journal of Educational Research, 66, 263-267.

Perkell, J., Guenther, F. H., Lane, H., Matthies, M. L., Perrier, P., VICK, J., ET AL. (2000). A theory of speech motor control and supporting data from speakers with normal hearing and with profound hearing loss. Journal of Phonetics, 28, 233-272.

Perkell, J., Lane, H., Svirsky, M. A., \& Webster, J. (1992). Speech of cochlear implant patients: A longitudinal study of vowel production. Journal of the Acoustical Society of America, 91, 2961-2979.

Perkell, J., Matthies, M. L., Lane, H., Guenther, F. H., WilhelmsTricarico, R., Wozniak, J., \& Guiod, P. (1997). Speech motor control: Acoustic goals, saturation effects, auditory feedback and internal models. Speech Communication, 22, 227-250.

Perkell, J., Matthies, M. L., Svirsky, M. A., \& Jordan, M. I. (1995).
Goal-based speech motor control: A theoretical framework and some preliminary data. Journal of Phonetics, 23, 23-35.

Postma, A. (2000). Detection of errors during speech production: A review of speech monitoring models. Cognition, 77, 97-131.

WeLls, J. C. (1982). Accents of English 2: The British Isles. Cambridge: Cambridge University Press.

\section{NOTES}

1. Strictly speaking, consonant and vowel realizations are involved in prosodic differentiation too, but the judgment of standard or nonstandard consonants or vowels focuses on stressed syllables and, thus, is analytically separable from prosodic judgments.

2. A group of four speakers from Yorkshire (two who had retained and two who had lost their accent) was also included. Similarity judgments were obtained about these speakers in the same way as for the other speakers. Preliminary analyses of these data, along with the data for the five accent groups used in Experiments 1 and 2, showed that each of the five groups selected for analysis here was grouped separately. The speakers in the group from Yorkshire were not discriminable on the basis of the similarity judgments from the HC group. Since there was no way of assessing accent shifts in this group, they were dropped from subsequent analysis. Note that this does not mean that there is no Yorkshire accent, but only that the similarity judgments did not reflect the accent in this case. 


\section{APPENDIXA \\ Descriptive Breakdown of the Accent Features}

\section{Phonetic Properties of the Features}

Due to the phonetic variation in the realization of functionally equivalent elements, dialect and regional accent comparisons cannot easily be based directly on phonetic representations but require a tertium comparationes to which the phonetic statement can be related. In general, we follow this convention by referring to keywords used by Wells (1982) or Hughes and Trudgill (1996) and then describing phonetically what is meant by the word in terms of accent variation. However, when an accent feature can be identified directly by giving its phonetic symbol or description, we do so.

1. Putt-put $( \pm / \Lambda /)$. In Northern English accents, the $/ \Lambda /-/ \mho /$ opposition distinguishing putt $/ \mathrm{p} \Lambda \mathrm{t} /$ from put /put/ does not exist; the two words are homophones. Phonetically, the single vowel can have a [U] quality, but educated Northern speakers often have a single midcentral quality.

2. Fair-fur ( $\pm / 3 \mathbf{3} /)$. The lack of opposition between fair and fur words. The realization of words that, in $\mathrm{HC}$ English, contain the /3:/ phoneme as [ $\varepsilon:$ ] is typical for Liverpool speakers.

3. [a]-glass $( \pm / \mathrm{a} /)$. There are many words (last, aunt, pass, etc.) that have a short-A vowel in Northern British accents, with a more open and retracted [a] quality than in HC English /æ/, where HC English has a long A with a quality close to Cardinal Vowel 5 ([a: $]$ ).

4. Happy $( \pm[i])$. Unstressed $-y$ endings to words vary in their quality from a close [i]-like quality, typical of HC English, to a more open and centralized [I] or, sometimes, even centralized [ê]. Of the accents investigated, $\mathrm{SC}$ and NI accents are typically characterized by a more open [I]-[ê]] quality.

5. Stop-(af)frication ( \pm affr). The lax articulation of (particularly) apical and velar stops in some dialects (e.g., LI) results in affricate or even fricative realization: $/ \mathrm{t} /$ as $[\mathrm{ts}]$ and $/ \mathrm{k} /$ as $[\mathrm{x}]$ or $[\chi]$.

6. Tapped /r/ ( $\pm[r])$. SC, NI, and some Northern accents have an apical tapped /r/ ([r]) intervocalically (e.g., very $[$ veri]).

7. Postvocalic /r/ ( \pm rhot). Accents are often distinguished along the \pm rhotic dimension, meaning that $/ \mathrm{r} /$ is pronounced (as $[\mathrm{I}]$ or as $[\mathrm{r}]$ ) postvocalically before a consonant or finally (e.g., cart [ka:.st] or car [ka:..]).

8. Rhotic $/ \mathrm{t} /( \pm \mathrm{t}[\mathrm{I}])$. A number of urban accents in Northern England have a $[\mathrm{I}]$ realization of intervocalic, poststress /t/ (e.g., got a or got to ['gD.sp] or better ['be.ıə]. This probably developed via a weakened "tapped" or "flapped"/t/ ([r]) but is now, as a postalveolar, even slightly retroflex approximant, phonetically distinct from it.

9. $<\mathrm{ng}>( \pm[\mathrm{gg}] / \pm[\mathrm{n}])$. Some Northwestern accents (LI, in this study) have no $/ \mathrm{y} / \mathrm{and} / \mathrm{ng} /$ alternation (e.g., sing /sin/, singer/sina/ versus finger/finga/); they realize all $<\mathrm{ng}>$ sequences as $/ \mathrm{ng} /$. Some accents (NC, SC, and NI here) maintain a $/ \mathbf{y} /-/ \mathbf{y g} /$ alternation intervocalically but realize unstressed word-final /In/ as [In].

10. Diphthongs ( \pm diph/ \pm centr). The /eI/ and /əv/ diphthongs are typically realized as wide diphthongs [e̦ 1 ] and [30], respectively, in the HC English accent [+ $\operatorname{diph}(w)]$, whereas SC and NI English are typically monophthongal [e:] and [o:]: - diph, and LI is a narrower diphthong than standard, [eI] and [ev]: +diph(n). The NC accent has a distinctive centering, instead of a closing gesture, [eə] and [oə]: $+\operatorname{diph}(\mathrm{c})$.

11. /l/-alternation ( $\pm[\mathrm{\jmath}]$ ). HC English is characterized by a contextually determined alternation of a "clear" /l/ and a dark /1/ ([ł]), with the former, a slightly palatalized realization, occurring pre- and intervocalically, whereas the latter, a velarized variant, occurs postvocalically. In the accents examined, this alternation also occurs in the LI variant, but in the NI and the NC accents all /1/ realizations tend to be clear [1], and in the SC accent they tend to be dark ([1]).

12. Lot $[0]( \pm[\supset])$. In the HC English accent, the short rounded, open back vowel in the lot words (/p/) is both qualitatively and quantitatively different from the vowel in thought words (/o:/). SC and NI accents typically do not distinguish the quality of these vowels, producing a more open $/ \mathrm{o}: /$ and a less open $/ \mathrm{v} /$ than in the standard accent.

13. $/ \mathrm{h} /$-dropping $( \pm / \mathrm{h} /)$. Although $/ \mathrm{h} /$ is generally dropped in unstressed syllables, only the LI accent (among those examined here) has no $/ \mathrm{h} /$ phoneme and, therefore, no $[\mathrm{h}]$ realization in stressed syllables.

14. Talk/a:/ ( $\pm[\mathrm{ar}])$. The NC accent is characterized by the incidence of /ar/ instead of $/ 0 \mathbf{z} /$ in words such as talk, grouping them with palm instead of with caught.

15. Glottaling ( $\pm[?])$. The tendency to reinforce postvocalic or even intervocalic voiceless plosives and to replace /t/ by [?], particularly syllable-finally when followed by another consonant, is typically found in SC, $\mathrm{NI}$, and NC speech. In the latter, the closure and the release of the glottal constriction is later than the formation and release of the accompanying oral closure. In HC English, the occurrence is increasing and may soon not be regarded as substandard. In LI English, glottaling is rare.

16. $/ \mathrm{i} \mathrm{i} / \mathrm{and} / \mathrm{u} \mathrm{z} /$ diphthongization $( \pm[\mathrm{i}:])$. Independent of the quality of their phonemic diphthongs, the accents differ in their tendency to diphthongize the monophthongs $/ \mathbf{i} / /$ and / $\mathbf{u} / /$ as [IÎ] and [Ut], respectively. SC and NI accents tend to have more clearly monophthongal realizations than do HC, LI, or NC accents.

17. What $/ \mathrm{M} /( \pm[\mathrm{M}])$. A phonemic distinction between $<w h>$ and $<\mathrm{w}>$ words exists in $\mathrm{SC}$ and NI accents (whether / меðð/ is distinct from weather/weðx/), in contrast to the other accents examined here. 
APPENDIXA (Continued)

II. Distribution of Accent Features Among the Regional Accents Examined

\begin{tabular}{|c|c|c|c|c|c|c|c|c|c|}
\hline & \multicolumn{9}{|c|}{ Feature } \\
\hline & 1 & 2 & 3 & 4 & 5 & 6 & 7 & 8 & 9 \\
\hline Liverpool & $-/ \Lambda /$ & $-/ 3 \mathbf{i} /$ & $+/ \mathbf{a} /$ & $+[\mathrm{i}]$ & $+\mathrm{affr}$ & $+[\mathrm{r}]$ & - rhot & $+\mathrm{t}[\mathrm{I}]$ & $+[\mathrm{gg}]$ \\
\hline Newcastle & $-/ \Lambda /$ & $+/ 3 i /$ & $+/ \mathrm{a} /$ & $+[\mathrm{i}]$ & - affr & $-[\mathrm{r}]$ & - rhot & $-\mathrm{t}[\mathrm{I}]$ & $-[\mathrm{gg}]$ \\
\hline Scotland & $+/ \Lambda /$ & $+/ 3 \mathbf{m} /$ & $-/ \mathbf{a} /$ & $-[\mathrm{i}]$ & - affr & $+[\mathrm{r}]$ & + rhot & $-\mathrm{t}[\mathrm{I}]$ & $-[\mathrm{gg}]$ \\
\hline Northern Ireland & $+/ \Lambda /$ & $+/ 3 \mathbf{z} /$ & $-/ \mathrm{a} /$ & $-[\mathrm{i}]$ & - affr & $-[\mathrm{r}]$ & + rhot & $-\mathrm{t}[\mathrm{I}]$ & $-[\mathrm{gg}]$ \\
\hline \multirow[t]{3}{*}{ Home counties } & $+/ \Lambda /$ & $+/ 3 \mathbf{m} /$ & $-/ \mathrm{a} /$ & $+[\mathrm{i}]$ & - affr & $+[\mathrm{r}]$ & - rhot & $-\mathrm{t}[\mathrm{I}]$ & $-[\mathrm{yg}]$ \\
\hline & \multicolumn{9}{|c|}{ Feature } \\
\hline & 10 & 11 & 12 & 13 & 14 & 15 & 16 & 17 & \\
\hline Liverpool & $+\operatorname{diph}(\mathrm{n})$ & $\pm[1]$ & $-[0]$ & $-/ \mathrm{h} /$ & $-[\mathrm{a}:]$ & $-[?]$ & $-[\mathrm{i}:]$ & $-/ \mathrm{M} /$ & \\
\hline Newcastle & $+\operatorname{diph}(\mathrm{c})$ & $-[\mathrm{l}]$ & $-[0]$ & $+/ \mathrm{h} /$ & $+[\mathrm{a}:]$ & $+[?]$ & $-[\mathrm{i} i]$ & $-/ \mathrm{M} /$ & \\
\hline Scotland & - diph & $+[\mathrm{ł}]$ & $+[0]$ & $+/ \mathrm{h} /$ & $-[\mathrm{a}:]$ & $+[?]$ & $+[\mathrm{i}:]$ & $+/ \mathrm{M} /$ & \\
\hline Northern Ireland & -diph & $-[1]$ & $+[0]$ & $+/ \mathrm{h} /$ & $-[\mathrm{a}:]$ & $+[?]$ & $+[\mathrm{i} i]$ & $+/ \mathrm{M} /$ & \\
\hline Home counties & $+\operatorname{diph}(w)$ & $\pm[1]$ & $-[0]$ & $+/ \mathrm{h} /$ & $-[\mathrm{a}:]$ & $-[?]$ & $-[\mathrm{i} i]$ & $-/ \mathrm{M} /$ & \\
\hline
\end{tabular}




\section{APPENDIX B \\ Texts Used in the Experiments, With Critical Features Indicated}

\section{Text 1: "The Pain of Hospitality"}

When the foreign guests trooped out onto the lawns of the manor gardens, Lady Hamilton

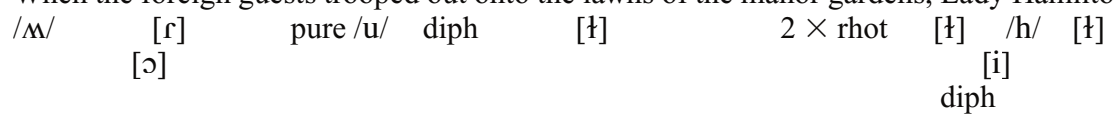

shuddered at the vision of scuffed grass, dirty plates and glasses scattered around the grounds

$$
\begin{aligned}
& / \mathrm{h} / \mathrm{L} / \mathrm{h} / \mathrm{a} / \mathrm{rhot} \quad / \mathrm{a} /[\mathrm{P}] \quad[\mathrm{r}] \quad[\mathrm{r}] \\
& / \mathrm{t} / \operatorname{diph} / \mathrm{t} / \mathrm{diph} \operatorname{diph} \\
& \text { [r] } / 3: /
\end{aligned}
$$

that would greet her when the garden-party was over. The look the butler gave her after

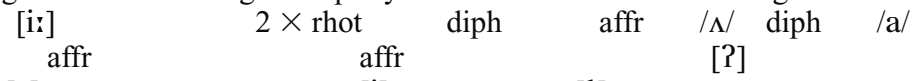

$$
\text { [r] [i] [ [ ] }
$$

the last summer gathering of the company directors, she would never forget. And the maids
$/ \mathrm{a} / / \mathrm{\Lambda} /$
[ng]
$/ \mathrm{h} /$
$[\mathrm{r}]$
affr diph

$\begin{array}{ccc}{[\mathrm{l}]} & {[\mathrm{r}]} & {[\mathrm{i}]} \\ \text { were talking, more than a week after everyone had gone, about the Boston "gentleman" who }\end{array}$
[a:]
rhot
[i:] /a/
[r]
[ว]
[?] $/ \mathrm{h} /$ affr

affr

[0] [1]

was caught "groping." Just cleaning up the house and grounds had taken over a week!

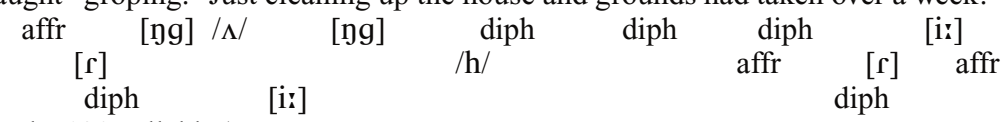

(91 words; 130 syllables)

(1)

Text 2: "Risky Business"

She was doing well. The days of careful planning had payed off. If she hurried she could

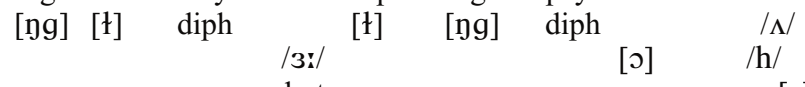

$$
\begin{aligned}
& \text { rhot [r] }
\end{aligned}
$$

even get a light lunch from the stall in the park, and then walk across the grass to the south

$\begin{array}{cccccc}\mathrm{t}[\mathrm{I}] \mathrm{affr} & {[\mathrm{l}]} & \text { affr } & \mathrm{affr} & / \mathrm{a} / & \mathrm{diph} \\ 2 \times[\mathrm{l}] / \mathrm{\Lambda} / & & \text { rhot } & {[\mathrm{a}:[\mathrm{r}]} & {[\mathrm{r}]} \\ \operatorname{diph} & & & {[\mathrm{o}]} & \end{array}$

gate. When she would next eat was hard to say. So far, nothing had gone wrong. How to get $/ \mathrm{P} / \mathrm{affr}$

$/ \mathrm{M} /$

$\begin{array}{cccc}/ \text { P/affr } & \text { rhot } & \text { rhot } \\ {[\mathrm{ii}]} & / \mathrm{h} / & \operatorname{diph}]\end{array}$

$2 \times[\circ] \operatorname{diph}$

past the person standing at the door was another matter though. If she got caught, she was to /a/ $/ 3: / 4$ rhot $/ \mathrm{yg} / / 2 / \mathrm{affr}$ diph affr talk as little as possible, and answer naively: She had come to the wrong house, a silly
$2 \times$ affr $[1]$
[a:]
[ว]
[ł] /a/
[i]
$/ \Lambda /$
[o] $/ \mathrm{h} /$
[i]
[ᄃ] diph [ł]

mistake anyone could make.
affr
affr
diph
diph
(95 words; 117 syllables) 